\title{
Efficacy of Replacing the Lecture with a SKILL in Engineering Science Courses
}

\section{Libby Osgood P. Eng, UPEI \& Dalhousie University}

Libby Osgood is an Assistant Professor at the University of Prince Edward Island in Canada, where she teaches dynamics and design courses. Concurrently, she is pursuing her $\mathrm{PhD}$ in Mechanical Engineering at Dalhousie University in Halifax, Nova Scotia. Her research interests include active learning pedagogy, service learning, and social justice.

Dr. Clifton R Johnston, Dalhousie University 


\section{Efficacy of Replacing the Lecture with a SKILL in Engineering Science Courses}

Active learning techniques within engineering science courses engage students and improve retention of information. However, these techniques rely on a lecture to deliver course content which appeals only to auditory learners. In order to accommodate visual and kinesthetic learners, a learning method should be developed to replace the lecture and to provide emphasis for certain topics within an engineering course. A structured kinesthetic independent learning lab (SKILL) was developed to allow students to discover scientific topics in a more tactile way.

The lecture-free, hands-on learning approach was delivered at University of Prince Edward Island and Dalhousie University in two engineering science courses in the 2013-2014 academic year. Data were collected to measure the efficacy of the technique as compared to a traditional lecture in multiple forms: assignments, quizzes, and exams to measure actual learning and a satisfaction survey to measure perceived learning and preferred delivery method (lecture or SKILL). Forty-six first-year and twenty-nine second-year engineering students learned two topics in their respective courses and it was found that $42 \%$ of 45 responding students preferred the SKILL compared to $33 \%$ of students who preferred the lecture. High performing students (85\%-100\% course grade) prefer lecture while students who perform in the middle range (50 $84 \%$ ) prefer the SKILL ( $\mathrm{p}<.05$ ). There was no statistically significant difference in actual learning of either the SKILL or the lecture, affirming the continued development of SKILLs as a way to emphasize material and better facilitate mid-performing and kinesthetic learners.

\subsection{Introduction}

In order to increase student engagement and knowledge retention in an engineering course, active learning techniques such as the inverted classroom, problem (or project) based learning, think-pair-share, and sixty-second essays are often employed. However, traditional engineering science courses continue to rely on lectures to transmit new knowledge and concepts, even when employing active learning techniques. For example, in an inverted classroom ${ }^{1}$, lectures occur outside of the class, leaving class-time to answer questions and work on problems, but this model is still dependent upon lectures. Shorter active learning techniques such as think-pair-share and sixty second essays allow students to understand or respond to a particular topic within a lecture, but do not replace a lecture. Inquiry-based methods such as just-in-time teaching and projectbased learning are best suited for design courses rather than engineering science courses ${ }^{2}$ due to the focus on process and integration of skills across the curriculum. Problem-based learning ${ }^{2}$ has a similar advantage of integration, but isn't used for dissemination of new information. Even gamification $^{3}$, an active learning technique that turns completing the assignments into a game, requires students to attend lectures. More developments need to be made to find an alternative to the didactic lecture, especially in engineering science courses.

There are active learning techniques used in engineering science courses that do not require a lecture, such as programmed instruction ${ }^{4}$, study guides ${ }^{5}$, annotated outlines ${ }^{6}$, and processoriented guided inquiry learning (POGIL) ${ }^{7}$. However these methods only accommodate auditory and visual learners, leaving the $15 \%$ of students who learn through kinesthetic methods ${ }^{8}$ to rely on their secondary learning method. Discovery learning ${ }^{2}$, a more radical free-form technique that 
doesn't require a lecture, can have unpredictable results ${ }^{2}$, which could negatively impact student learning if that class is the only opportunity to learn the material. A more structured approach is required to teach to the entire class, delivering content in multiple formats ${ }^{8}$. This necessitates a guided, lecture-free, active-learning technique, inclusive of kinesthetic learners. This paper will discuss the development and efficacy of four structured, kinesthetic independent learning labs (SKILLs) used at the University of Prince Edward Island (UPEI) and Dalhousie University in the 2013-2014 academic year in two engineering sciences courses: a second-year Dynamics course and a first year Introduction to Engineering Analysis course.

\subsection{Structured Kinesthetic Independent Learning Lab (SKILL) Measurement Methodology}

The SKILL consists of a 5 minute introduction explaining the planned activities and presenting the topic. Students progress through physical stations around the room with one or two learning objectives at each station, walk through the derivation of concepts, and perform example problems in a facilitated, experiential method. Each station contains an example of a real world problem where the students manipulate objects in order to learn as well as answers to the step in the handout they received.

\subsection{Development of SKILL Material}

In order to develop a SKILL, as when developing any course material, the starting point must be the objectives for that activity. The SKILLs must be:

- structured

- kinesthetic/tactile

- lecture-free, and

- content-driven.

Because the SKILL is so different from a typical class, emphasis can be given on a particularly difficult or abstract topic. The structured nature of the SKILL ensures understanding of fundamental concepts must be understood before students can proceed to the numerical portion, putting more emphasis on the abstract portion of the learning that may be easily ignored during a lecture. Follow these steps to create a SKILL:

1. Start with a list of content objectives (appendix A-1 for sample Momentum SKILL objectives).

2. Group and order the objectives, starting with more fundamental topics and moving to the more complex concepts.

3. Document the important points. The SKILL is not intended to replace the textbook, but rather what is said during lectures. This can include derivations, definitions, solving small problems, and eventually solving one complex problem.

4. Turn the points into small numbered problems, with a blank or something for students to do for each small step. This can include quick lab activities such as measurements or timing.

5. Break the room up into stations, one for each major concept.

6. Add tactile opportunities to each step. Find something hands on to help deliver that specific content. This can include a soft ball and a rubber ball to show the difference between elastic and inelastic. While the difference sounds obvious, attaching the memory 
of throwing the two against a table or wall will help solidify the difference to the students. A newton's cradle is used in many SKILLs as it's simple but has so many physical applications.

7. Estimate time for each step and ensure total is within 2 hour time limit.

8. Print a hard copy for the students with blanks and print one copy with the answers. (Appendix A-2 contains a sample student handout with answer key). Divide the answers into their appropriate stations and put them around the room, so students have to physically stand up and go from station to station to manipulate the objects and verify their answers are correct. (Include cover sheets so the answer isn't obvious from a distance).

9. Invite the students in and circulate to discuss difficult points and ensure students aren't jumping ahead. Remind the students that though they can take the handouts, they should write the important points in their notebook just like they would in a lecture.

10. In the next class, reiterate the important points from the previous class (as would be performed in any lecture).

\subsection{Description of Sample SKILL}

To better understand how to implement the SKILL, this section will focus on the development and execution of a SKILL in the Dynamics class at Dalhousie University. Momentum was chosen as one of the SKILL topics as students often confuse impulse and impact and how to categorize types of impact. Appendix A-1 lists the primary objectives for the SKILL that all 14 students experienced during the 2-hour lab time. The SKILL could be held in any type of room, as the hands on activities are small enough to manipulate and can be placed on a desk in a tiered classroom or on a table in a flat room. The only requirement is to distribute the activities around the room to encourage students to move from one section to the next. Also, the SKILL is easy to administer during a normal lab time as students work at different paces and arrive to class at different times. Thus, students automatically stagger themselves and prescribing a specific time is not necessary. Materials for this lab are available educational toys: a few rubber balls, a tennis ball, a newton's cradle, a ruler, and a stopwatch. The kinesthetic aspect of the lab isn't required to be groundbreaking or unfamiliar, just needs to link a specific hands-on activity to an abstract concept.

Appendix A-2 shows the handout that is used to facilitate the third of the four objectives of the SKILL: central impact. The students are given a handout for all four sections when entering the room (without the highlighted yellow answers), and one handout is distributed around the room with the highlighted yellow answers and a cover sheet, requiring students to work on each section before checking their answers and proceeding to the next section. This allows for incremental learning and verification of concepts in order of increasing complexity. The handson activities are placed with the answers so students move around the classroom. In step 1, students use two rubber balls to simulate the different phases of collision. Step 2 is the derivation of the coefficient of restitution. Step 3 is an experimental application of restitution, asking students to measure the angles that the balls achieve for a newton's cradle and work through a problem. If this were a lecture, a similar example problem would be shown on the board, but this way, students work out the steps on their own. The other three objectives are introduced in a similar way and the full handout and all SKILL materials are available upon request. 


\subsection{Study Methodology}

In the 2013-2014 academic year, four SKILLs were developed for two different courses at two universities. In the first class at UPEI, a first-year Introduction to Engineering Analysis course, students were introduced to Strength of Materials and Energy topics. Half of the class of 46 students learned the first topic with a SKILL while the other half worked on problems. The groups were reversed for the second topic. In the second class at UPEI, a Dynamics course, students all learned the work and energy topic using a SKILL and momentum topic using standard lectures, due to the small class size of 15 . The following summer at Dalhousie, 14 students taking Dynamics experienced the reverse. Therefore there were two control groups and two experimental groups for each class.

The standard lecture-based delivery consisted of two - 50 minute lectures where the topic were introduced and problem examples were worked out on the board. This was followed up with a problem lab where students had 2 hours to work on a difficult problem relating to the topic in groups. The SKILL occurred during a 2 hour lab, taking up half the time of the lecture-based delivery. In both scenarios, students took a concept quiz to measure their learning during the next class, completed a set of homework problems within one week of the lab, and took an exam within a month of the lab. These items were used to measure student learning in order to determine whether the SKILL was as effective as a standard lecture. After course grades were completed, students were emailed a short instrument (appendix A-3) asking them to rate their perceived understanding of the two topics, select which method was preferred, and state their enjoyment of the two delivery techniques (lecture and hands-on). This information will correlate perceived and actual learning, and student enjoyment and efficacy of the technique.

\subsection{Participant Data}

Of the 75 students enrolled in the courses, 45 students responded to the satisfaction survey. Participant data are shown in Table 1. 'Topic 1' refers to the group of students that participated in the SKILL for topic 1 (Strength of Materials for $1^{\text {st }}$ year students and Energy for $2^{\text {nd }}$ year students) and the lecture for topic 2 (Energy for $1^{\text {st }}$ year students and Momentum for $2^{\text {nd }}$ year students). 'Topic 2' refers to the remaining students who started with a lecture and learned the second topic using the SKILL. It should be noted that the students in topic 2 for year 2 are students taking summer courses, many of whom took the course previously. This could skew the data due to an uncharacteristic population. An additional source of bias could be the low response rate from this group.

The satisfaction survey contains 18 mixed-methods items. A qualitative item codes comments

\begin{tabular}{|c|c|c|c|c|c|}
\hline \multirow{5}{*}{ 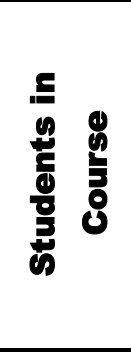 } & Total & 75 & 46 & & 29 \\
\hline & $\begin{array}{l}\text { Topic } 1 \text { SKILL } \\
\text { Topic } 2 \text { Lecture }\end{array}$ & 38 & 23 & ( $50 \%)$ & $15(52 \%)$ \\
\hline & $\begin{array}{l}\text { Topic } 1 \text { Lecture } \\
\text { Topic } 2 \text { SKILL }\end{array}$ & 37 & 23 & $(50 \%)$ & $14(48 \%)$ \\
\hline & Female & 17 & 10 & $(22 \%)$ & $7 \quad(24 \%)$ \\
\hline & Male & 58 & 36 & $(78 \%)$ & $22(76 \%)$ \\
\hline \multirow{3}{*}{ 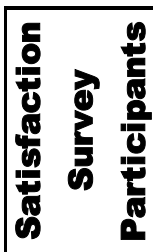 } & Subtotal & 49 & 28 & $(61 \%)$ & $21 \quad(72 \%)$ \\
\hline & $\begin{array}{l}\text { Topic } 1 \text { SKILL } \\
\text { Topic } 2 \text { Lecture }\end{array}$ & 29 & 14 & ( $50 \%)$ & $15(71 \%)$ \\
\hline & \begin{tabular}{|l} 
Topic 1 Lecture \\
Topic 2 SKILL
\end{tabular} & 20 & 14 & ( $50 \%)$ & $6 \quad(29 \%)$ \\
\hline
\end{tabular}


regarding preference of delivery (lecture or SKILL) into four points: SKILL, Lecture, Both, or Other. There are 5 quantitative items ( 2 negatively worded) to determine how much students enjoy hands-on topics as compared to lectures, with a left anchored 4-point scale. These 5 items are averaged to create a 'Total Enjoyment' variable. In order to measure perceived learning, there are 6 items asking students to rate their knowledge on 6 of the objectives for topic 1 or 2 on a left anchored, 4 point scale. Two variables average the 6 items measuring perceived knowledge and are renamed 'Total Perceived Knowledge'. Two variables averaging the measured knowledge for topic 1 and 2, renamed 'Total Measured Knowledge', were developed from the homework, quizzes, and exams on a left-anchored 4 point scale. There are between 5 and 20 quantitative items for each topic depending on the student and class. Grades are converted to the 4-point scale using the divisions: $85 \%-100 \%, 70 \%-84 \%, 50 \%-69 \%$, and $<50 \%$. This maintains a left-anchored 4-point scale for all items. None of the five total variables were deemed reliable (Chronbach's $\alpha$ was less than 0.7 for each), possibly due to a small sample size and variability in the answers. Though the total variables are not reliable, they can be indicative of correlations and used in future studies with larger sample sizes. An analysis of variances (ANOVA) was performed for each 38 items separately and the five total knowledge variables.

\subsection{Results}

The results from an analysis of variance (ANOVA) are encouraging and show statistical significance between desired learning method and course grades $(\mathrm{p}=.033, \mathrm{n}=45)$. Ten out of 18 students with the highest course grades preferred learning through the lecture rather than the SKILL, as shown in figure 1 . This is expected as engineering science courses are traditionally taught with a lecture, so students with good grades would prefer the lectures and should perform well. What is interesting is that 15 out of 25 students with a course grade between $50 \%$ and $84 \%$ prefer the SKILL to lecture. This is the demographic that the SKILL was developed to target, so

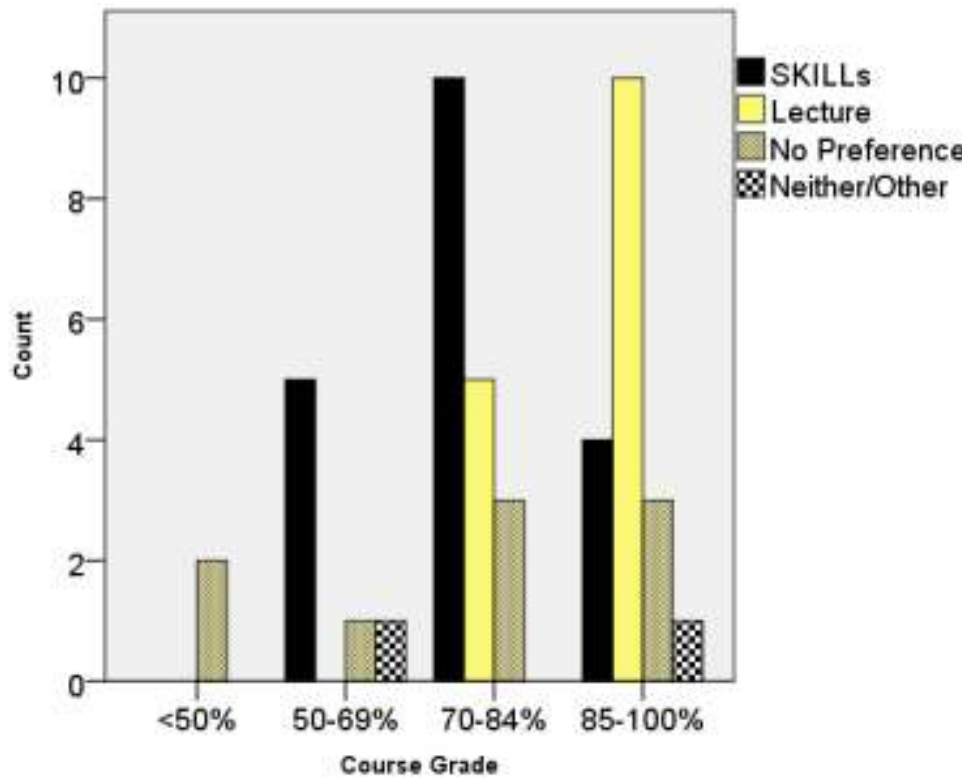

Figure 1: Preferred teaching method by course grade it is encouraging that the targeted students preferred a more hands-on method. Not one student in the 50$69 \%$ demographic selected lecture as their desired learning method $(n=7)$.

Whereas the preferred learning method specifically addresses this one experience with a SKILL and lecture, students were also asked questions regarding their preferred learning style overall. As expected, there was a correlation $(\mathrm{p}<.01)$ between students who preferred the SKILL and those who prefer hands-learning as opposed to lecture. 
As shown in figure 2, one correlation revealed that $45 \%$ of responding female students $(\mathrm{n}=11)$ preferred the lecture to the SKILL, whereas $47 \%$ of male students $(n=34)$ preferred the SKILL to the lecture. While this was not statistically significant, there was a difference of $0.25 / 4$ between the means. This correlation confirms the previous development linking grades to preference, as the female students had an average course grade $5 \%$ higher than the average course grade for male students.

This has addressed the first part of the question regarding preference. Next the perceived and measured knowledge must be

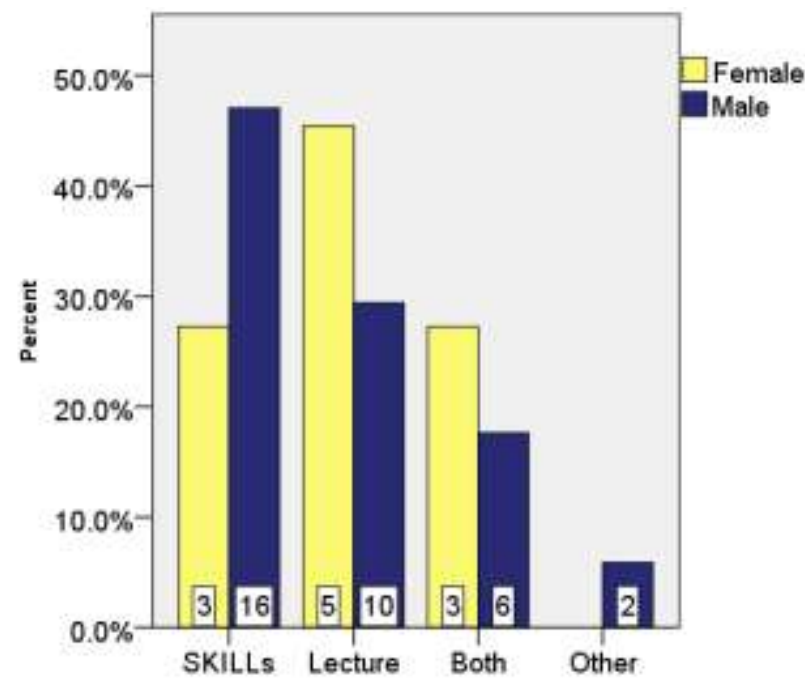

Figure 2: Gender preference of delivery method considered. Students who learned through the SKILL for topic $1(n=29)$ had a perceived mean knowledge 0.25/4 higher than their actual mean knowledge but their perceived and measured mean knowledge were equivalent in topic 2. Students who learned through the SKILL for topic 2 $(n=16)$ showed higher perceived mean knowledge than measured mean knowledge, though a smaller difference in averages (0.02/4). This increased confidence in abilities from hands-on learning is encouraging, that perhaps with further refinement, the SKILL could be as effective as a lecture. At the very least, there was little difference in performance between the two groups, despite the second group having a higher mean course grade (0.20/4 higher). Perhaps with a larger sample size and more balance between the two sample sizes (29 compared to 16), more information can be obtained.

\subsection{Conclusion}

Four hands-on, guided, tactile SKILLs were developed to offer students an alternate way to learn material without requiring a lecture. Based on student feedback favoring the SKILL (19/45 responses) and no significant difference of assignment grades between the SKILL and the lecture topics, the SKILLs are considered successful.

Two potential sources of error must be considered. First, student response rate was $60 \%$. The data likely reflects strong opinions for or against the SKILL and perhaps the 'no preference' option would have been higher if responses were required from all participating students. Additionally, the PI was the course instructor and though the surveys were not administered by the instructor until after course grades were submitted, students may have felt compelled to be more positive towards the new SKILLs. In order to provide more confidence in the results, a larger sample size should be employed in a follow on study. Either the items should be reviewed to ensure reliability of scale, or a technique must be found to standardize multiple class assignments and exams. Additional future work is to link student learning style to SKILL satisfaction, giving students a questionnaire to identify learning style. 
Different types of activities within an engineering science course will keep the students engaged and excited about class. If the entire course were SKILLs, the hands-on nature would destroy the novelty. The 9 students that selected 'both' as their preferred method commented that they prefer the combination, advocating for more tactile opportunities. Comments include:

The change of pace was nice.

I like the structure of lecture and working through the lab.

I can work hands-on at my own, slow pace. I think my recall was better.

Therefore, a combination of teaching methods is suggested, in order to balancing the course and adapting to all learning styles. While it is a challenge to cover content while employing timeconsuming active learning techniques, a SKILL can be implemented to emphasize important course objectives that may be difficult to convey with lecture. For example in engineering dynamics, collisions and modulus of elasticity are necessary to learn but often seen as obtuse by students. By having a SKILL on this topic, students were forced to spend time focusing on the different types of collisions before jumping into the equations. That focus on foundational knowledge before application can help illuminate difficult topics.

\subsection{Bibliography}

1. Lage, M. J., Platt, G J \& Treglia M, (2000). Inverting the Classroom: A gateway to creating an Inclusive Learning Environment, Journal of Economic Education, 31(1), 30-43.

2. Prince, M. J. \& Felder, R. M., (2006). Inductive Teaching and Learning Methods: Definitions, Comparisons, and Research Base, Journal of Engineering Education, 95(2).

3. Trivett, A., (2014). An Attempt to Gamify a First Course in Thermodynamics. Proceedings from the 2014 ASEE Annual Conference

4. Plants, H. L. \& Venable, W., (1975). Programmed Instruction vs. Conventional Instruction, Annals of Engineering Education 66(3), 244-246.

5. Khan, S. \& Dean, R. K., (1980). Elastically Structured Teaching With Study Guides. Proceedings from the 1980 ASEE Annual Conference.

6. Yokomoto, C. F. \& Ware, R. (1996). Using Annotated Outlines to Enhance Learning. Proceedings from the 1996 ASEE Annual Conference Proceedings

7. Douglas, E. P. \& Chiu, C. C., (2013). Implementation of Process Oriented Guided Inquiry Learning (POGIL) in engineering, Advances in Engineering Education, 3(3), http://advances.asee.org/vol03/issue03/03.cfm

8. Barbe, W.B. \& Milone, M.N., (1981). What We Know About Modality Strengths, Educational Leadership, 378380.

9. Felder, R.M. \& Silverman, L.K., (1988). Learning and Teaching Styles in Engineering Education, Journal in Engineering Education, 674-681. 


\section{Appendix A-1: Learning Objectives for Momentum SKILL}

a. Principle of Linear Impulse and Momentum

i. $\quad$ Define linear impulse $=$ force $*$ time

ii. Define linear momentum $=$ mass $*$ velocity

iii. Derivation of principle

iv. Componentize principle

b. Conservation of Linear Momentum

i. When to use the conservation equation.

ii. Use in conjunction with previous topics, conservation of energy, etc.

c. Central Impact

i. What is impulse vs impact?

ii. Define phases of impact: deformation, restitution

iii. Derive co-efficient of restitution

iv. Identify plastic vs elastic restitution

v. Practice use in conjunction with previous topics.

d. Oblique Impact

i. $\quad$ Define \& draw line of impact

ii. Identify oblique impact vs central impact cases

iii. Identify whether to use conservation of momentum for a system or for a particle

iv. Use in conjunction with conservation of energy, momentum, principle of energy, etc. 


\section{Appendix A-2: Objective C Handout (Answers Highlighted)}

\section{Central Impact ( 30 minutes)}

\section{Impact vs Impulse}

Impact is another word for collision, while impulse is a physical property: $\int_{t 1}^{t 2} \Sigma F d t$

Describe a situation where both impulse and impact occur.

In a collision between two balls (impact) the force * time of impact between them is the impulse.

Take 2 balls and simulate the phases of impact:
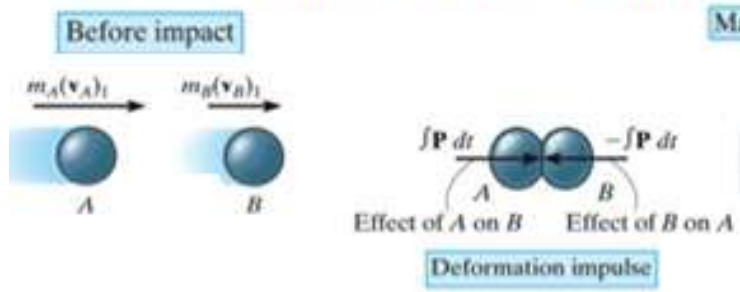

Maximum deformation

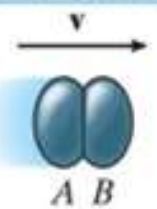

$\int \mathbf{R} d t$
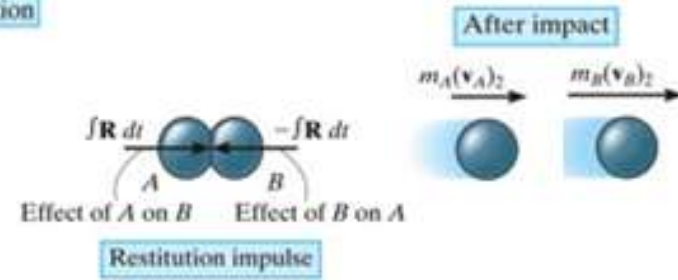

Restitution impulse

\section{Coefficient of Restitution}

The coefficient of restitution (e) is how efficiently the shape is restored after an impact. (See 15.4 for derivation). As a measure of efficiency, there are units.

$$
\begin{aligned}
& e=\frac{v_{B 2}-v_{A 2}}{v_{A 1}-v_{B 1}}=\frac{\text { Velocity change after impact }}{- \text { Velocity change before impact }} \quad \text { Notice that on top, the first value is of } \\
& \begin{array}{ll}
0 \leq e \leq 1 & e=0 \text { is perfectly plastic (pure deformation) } \\
e=1 \text { is perfectly elastic (nopemanent deformation) }
\end{array}
\end{aligned}
$$

Which phase of impact does plastic deformation get 'stuck' in?

Maximum deformation

Simulate plastic deformation with the balls. What happens with velocity of the balls after a plastic impact?

Velocitu of balls are same. Stick together. $0=v_{z 2}-v_{42}$

If masses are the same, velocity of balls switch. $V_{A 1}-v_{B 1}=v_{B 2}-v_{A 2}$

Simulate elastic deformation with the balls. If the balls have the same mass, what happens with velocity of the balls after an elastic impact?

\section{Application of Central Impact}

Using a Newton's cradle, find the coefficient of restitution between two balls ('remove' 3 balls).
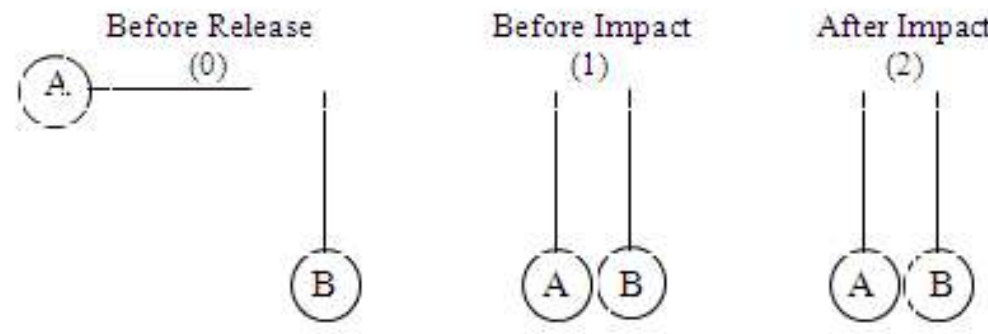

Max Height

(3)
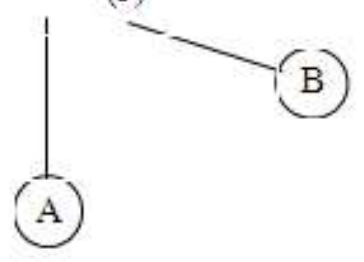
1. Lift ball $\mathrm{A}$ and measure angle: $\Theta_{\mathrm{A} 0}=$ and radius of string: $r=$

2. Use conservation of energy for ball A to find velocity of ball A just before impact ( $\left.\mathrm{v}_{\mathrm{A1}}\right)$.

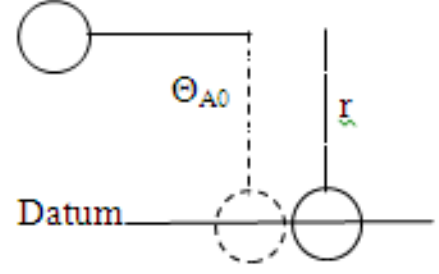

$$
\begin{aligned}
& T_{A 0}+V_{A 0}=T_{A 1}+V_{A 1} \\
& m g r \sin \theta_{A 0}=\frac{1}{2} m v_{A 1}^{2} \\
& v_{A 1}=\sqrt{2 g r \sin \theta_{A 0}}
\end{aligned}
$$$$
\text { Let } T_{A 0}=V_{A 1}=0
$$$$
\text { Rearrange for } V_{A 1}
$$$$
\text { For } r=13 \mathrm{~cm} \text { and } \Theta_{A 0}=90 \mathrm{deg}
$$$$
\mathrm{V}_{\mathrm{A} 1}=1.59 \mathrm{~m} / \mathrm{s}
$$

3. Release ball $\mathrm{A}$ and measure angle ball $\mathrm{B}$ achieves: $\Theta_{\mathrm{B} 3}=$

4. Use conservation of energy for ball $B$ to find velocity of ball $B$ just after impact ( $\left.v_{B 2}\right)$.

$$
\begin{array}{lr}
T_{B 2}+V_{B 2}=T_{B 3}+V_{B 3} & \text { Let } \quad \begin{array}{c}
T_{B 3}=V_{B 2}=0 \\
\frac{1}{2} m v_{B 2}^{2}=m g r \sin \theta_{B 3}
\end{array} \\
\text { Rearrange for } v_{B 2} \\
v_{B 2}=\sqrt{2 g r \sin \theta_{B 3}} & \text { For } \mathrm{r}=13 \mathrm{~cm} \text { and } \Theta_{B 3}=70 \mathrm{~d}=1.54 \mathrm{~m} / \mathrm{s}
\end{array}
$$

5. Find $\mathrm{v}_{\mathrm{A} 2}$ using Conservation of Momentum (can't assume it is 0 ).

$$
\begin{aligned}
m_{A} v_{A 1}+m_{B} v_{B 1} & =m_{A} v_{A 2}+m_{B} v_{B 2} & & \text { Since } m_{A}=m_{B} \text { and } v_{B 1}=0 \\
v_{A 1}+0 & =v_{A 2}+v_{B 2} & & \text { Rearrange for } v_{A 2} \\
v_{A 2}=v_{A 1}-v_{B 2} & =1.59 \frac{\mathrm{m}}{\mathrm{s}}-1.54 \frac{\mathrm{m}}{\mathrm{s}} & & v_{A 2}=0.05 \frac{\mathrm{m}}{\mathrm{s}} \text { if } \Theta_{B 3}=70 \mathrm{deg}
\end{aligned}
$$

6. Find e using Coefficient of Restitution equation. Is it plastic, elastic, or neither?

$$
e=\frac{v_{B 2}-v_{A 2}}{v_{A 1}-v_{B 1}}=\frac{1.54-0.05}{1.59-0}=0.94
$$

e is neither because $e \neq 1$ and $e \neq 0$, but nearly elastic

7. If you were to allow 3 collisions between the two balls, what would you expect the angle of ball $B$ to be? Measure it. Were you right?

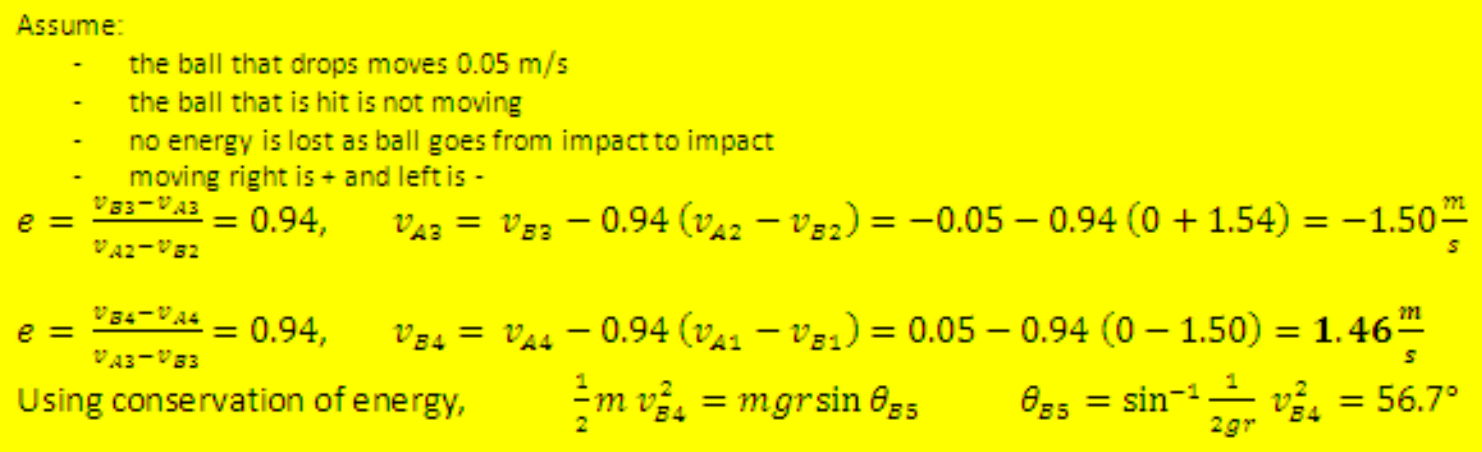

8. If you were to use 4 balls and the coefficient of restitution was consistent for all balls, what assumptions change and would you expect $\Theta$ to be higher or lower than in 7 ? Were you right? 


\section{Appendix A-3: Satisfaction Survey}

State how much you agree with the following statements regarding the hands-on lab that was on Chapter 15: Collisions, Impulse and Momentum for a Particle.

\begin{tabular}{|l|c|c|c|c|c|}
\hline & $\begin{array}{c}\text { Strongly } \\
\text { Agree }\end{array}$ & Agree & Disagree & $\begin{array}{c}\text { Strongly } \\
\text { Disagree }\end{array}$ & \\
\hline $\begin{array}{l}\text { 1. I learned as much during the lab as } \\
\text { I would have during lectures. }\end{array}$ & 1 & 2 & 3 & 4 & N/A \\
\hline $\begin{array}{l}\text { 2. I prefer the standard lecture with } \\
\text { examples. }\end{array}$ & 1 & 2 & 3 & 4 & N/A \\
\hline 3. I enjoyed the lab. & 1 & 2 & 3 & 4 & N/A \\
\hline 4. The lab was too long. & 1 & 2 & 3 & 4 & N/A \\
\hline 5. I get bored during lectures. & 1 & 2 & 3 & 4 & N/A \\
\hline
\end{tabular}

Rate how well you understand each of the following concepts:

\begin{tabular}{|c|c|c|c|c|c|}
\hline & $\begin{array}{l}\text { Completely } \\
\text { Understand }\end{array}$ & $\begin{array}{c}\text { Some } \\
\text { Questions }\end{array}$ & $\begin{array}{l}\text { Understand } \\
\text { a Little }\end{array}$ & $\begin{array}{l}\text { No } \\
\text { Idea. }\end{array}$ & \\
\hline \multicolumn{6}{|c|}{ Chapter 14: Energy and Work for a Particle } \\
\hline How to calculate work & 1 & 2 & 3 & 4 & $\mathrm{~N} / \mathrm{A}$ \\
\hline $\begin{array}{l}\text { When to use the Principle of } \\
\text { Work and Energy or the } \\
\text { Conservation of Energy }\end{array}$ & 1 & 2 & 3 & 4 & $\mathrm{~N} / \mathrm{A}$ \\
\hline How to calculate power in $\mathrm{hp}$ & 1 & 2 & 3 & 4 & $\mathrm{~N} / \mathrm{A}$ \\
\hline When work is positive & 1 & 2 & 3 & 4 & $\mathrm{~N} / \mathrm{A}$ \\
\hline Identify conservative forces & 1 & 2 & 3 & 4 & $\mathrm{~N} / \mathrm{A}$ \\
\hline How to calculate kinetic energy & 1 & 2 & 3 & 4 & $\mathrm{~N} / \mathrm{A}$ \\
\hline \multicolumn{6}{|c|}{ Chapter 15: Collisions, Impulse and Momentum for a Particle } \\
\hline How to calculate linear impulse & 1 & 2 & 3 & 4 & $\mathrm{~N} / \mathrm{A}$ \\
\hline $\begin{array}{l}\text { When to use the Principle of } \\
\text { Impulse and Momentum or the } \\
\text { Conservation of Momentum }\end{array}$ & 1 & 2 & 3 & 4 & N/A \\
\hline $\begin{array}{l}\text { The difference between central } \\
\text { and oblique impact }\end{array}$ & 1 & 2 & 3 & 4 & N/A \\
\hline $\begin{array}{l}\text { The difference between plastic } \\
\text { and elastic collisions }\end{array}$ & 1 & 2 & 3 & 4 & N/A \\
\hline $\begin{array}{l}\text { The difference between impact } \\
\text { and impulse }\end{array}$ & 1 & 2 & 3 & 4 & N/A \\
\hline $\begin{array}{l}\text { How to calculate the coefficient } \\
\text { of restitution }\end{array}$ & 1 & 2 & 3 & 4 & N/A \\
\hline
\end{tabular}

[Qualitative Assessment] Which method did you prefer? The hands-on lab or the lecture? Why? 